\title{
The Interdependence of Care and Autonomy
}

\author{
Joachim Boldt
}

\section{Introduction}

Since the 1960s, the principle of autonomy has increasingly been hailed as the cornerstone of medical ethics. Today, it is the prime focus of medical ethicists when assessing clinical research trials and therapy decisions at the bedside. Historically, this development is a reaction to scandalous medical research trials on humans in the mid-twentieth century. Experiments on humans in concentration camps in Nazi Germany as well as harmful and racist trials in the USA up to the 1970s clearly indicated that doctors were willing to disregard the will and well-being of individual patients in the name of what they declared to be scientific medical progress.

Apparently, the traditional ethos of the medical profession was not sufficient to prevent aberrations of this sort. The obligation not to perform any therapeutic or research intervention unless the patient is informed

\footnotetext{
J. Boldt $(\bowtie)$

Department of Medical Ethics and the History of Medicine, University of Freiburg, Freiburg, Germany 
and consents to the procedure was therefore introduced with great emphasis as an important, if not the most important, element of the medical profession's set of ethical norms. Although there were select earlier legal and ethical calls to incorporate patient consent into medical practice, the medical ethos prior to this development was mainly oriented towards not harming patients and, to the extent possible, promoting their well-being. Calls to respect the autonomy of patients thus entered the scene of medicine as part of an ethical orientation that, it was supposed, had not previously been included in the traditional medical ethos of caring for the well-being of patients.

This development has many effects on medical practice today. From an ethical standpoint, there is prima facie nothing wrong with strengthening the rights of patients in the medical encounter. On the contrary, if the traditional medical ethos lacks a focus on patient autonomy, and if medical ethics can help reinforce and justify the importance of patient autonomy, medicine ought to accept this new ethical orientation and incorporate it into its ethos. Most famously, the medical ethicists Beauchamp and Childress took this new orientation into account when setting up their set of biomedical ethical principles (Beauchamp and Childress 2013): Physicians ought to respect patient autonomy. In addition, they ought to minimise harm and maximise well-being, and finally, they ought to strive for the just distribution of scarce resources.

In what is to follow, I will argue that despite appearances, thinking of autonomy as a separate normative principle in addition to caring for well-being suffers from severe ethical drawbacks. What was and still is needed is instead a meaningful interpretation of the interdependence of autonomy and care, not a new principle besides care.

\section{A Conventional Limit to Autonomy in Medicine}

Numerous guidelines, regulations, conventions and laws spell out the details of what is implied by respect for autonomy in the medical context. The common understanding is that respecting autonomy entails a patient's right to refuse any medical treatment, regardless of whether the 
treatment appears medically necessary to restore health or, in the most extreme case, to save the patient's life. The right to autonomy is thus seen as a right of defence. Any medical intervention is an intervention into the patient's body, and no one ought to be allowed to directly intervene in the body of another person unless this person gives consent. At the same time, autonomy in the medical context does not mean that patients have a right to demand medical interventions that are not "medically indicated". That is to say, they cannot request interventions that, from a medical point of view, would not help to restore or maintain health, alleviate pain or suffering, or that would do more harm than good.

For those who presume that ethical rights ought to be consistently organised, this must come as a surprise. If patients are allowed to do harm to themselves by rejecting effective treatment, why should they not, in principle, have the right to request an intervention that does harm to themselves, and only to themselves, provided they are duly informed about any harms and benefits? Obviously, autonomy is counterbalanced in this case by another normative orientation. This orientation is a rudimentary form of the care perspective: Avoid doing harm to others. Although one may have to accept that someone may harm themselves by rejecting offers of help, inflicting harm on another person ought to be avoided, even if the request comes from the person themselves.

In health care, autonomy and care are thus balanced against each other. On the one hand, autonomy constitutes a right of defence against unwanted treatment, even if that treatment would lead to better health. On the other hand, care ensures that no therapeutically unnecessary harm is done to patients, even if they do make a corresponding request, and that medical interventions are restricted to restoring or maintaining health and to alleviating pain and suffering.

\section{The Thrust of the Autonomy Principle}

The practicability of these rules and regulations notwithstanding, this is an ethically puzzling situation. Taking John Stuart Mill's influential writings as the root of the current mainstream understanding of the autonomy principle, the basic idea of this principle is that individuals ought to 
be allowed to do whatever they want as long as their actions do not harm others: "The only freedom which deserves the name, is that of pursuing our own good in our own way, so long as we do not attempt to deprive others of theirs, or impede their efforts to obtain it" (Mill 1869, p. 13).

Autonomy here consists of the right to act in accordance with one's preferences and interests. This right is to be respected as long as carrying out the actions in question does not harm others. Mill assumes that a basic ability to distance oneself from overwhelming emotions, to sort interests, and to take factual information into account is a prerequisite of this right. "Unless he is a child, or delirious, or in some state of excitement or absorption incompatible with the full use of the reflecting faculty" (Mill 1869, chapter 5, p. 5), the freedom of the individual with regard to his or her own good is to be respected.

Now, by itself the autonomy principle does not convey any reason for why it is good to have a specific preference or why it is good to help others to have a preference apart from the fact that this is the other's preference. The autonomy principle does not provide an answer for someone asking themselves whether they should have a certain preference and why, nor does it offer guidance to someone who is in a position to provide support to another person and is wondering whether they should regard that person's preference as worthy of support.

It follows from the autonomy principle that one ought to be allowed to reject medical treatment, even if the treatment is medically advisable. It further follows that attempting to understand and perhaps alter a patient's preferences is unjustified, since the only justification for the preference is the fact that the patient holds this preference. A similar case can be made regarding assisted suicide and voluntary euthanasia. Taking one's own life primarily concerns oneself. Assuming that this act does not compromise the well-being of others, and assuming that one chooses this option as the result of a clear-minded process of reasoning on one's prospects, there is no justification for interfering with or objecting to this choice from the point of view of autonomy. What is more, if a person who is determined to commit suicide does not have the means or opportunity to do so, experts who have the required know-how could be justified in acting on this person's behalf on the basis of respect for autonomy. Asking the patient why he prefers to end his life in order to be able to understand and evaluate this preference must be seen as misguided. 
In accordance with this claim, when Mill is concerned with whether one person should be allowed to "counsel" another or "instigate" them to do something, he is not thinking about whether or not it is good, independent of the preferences one happens to have, to act in a certain way. He is concerned instead with whether people should be allowed to counsel others who share a preference that may be met with reproach at a societal level on how to best act in accordance with that preference. For example, should one be allowed to counsel someone who likes gambling on how best to gamble? Mill answers this question in the affirmative, provided the counsellor does not derive a personal benefit from his advice (Mill 1869, chapter 5, p. 8). Accordingly, following Mill, supporting someone else's preference to end their life is justifiable as long as one does not do so for personal gain. Still, and this is the important point, questioning this way of acting from a point of view independent of the preference one happens to have must be seen as pointless and, in addition, unjustifiable if one thereby aims to alter the preferences of the other person.

\section{Assessing Reasons for Doing What One Wants to Do to Oneself}

In order to conclude that it is good—not only from the point of view of an individual who has a certain preference but from a point of view independent of given preferences - to act in a certain way, the desired state of affairs must additionally be presumed to be good from some sort of interindividual standpoint. The term "inter-individual" here is meant to indicate that this point of view must refer to reasons that can appeal to more than just those who happen to have a specific preference. Utilitarian ethics, for example, clearly rests on the assumption that is always possible to supply this kind of inter-individual reason for acting one way rather than another.

The ethical debate concerning enhancement is a case in point. Enhancement is the use of pharmaceuticals and medical technologies by healthy people in order to improve their mental, emotional, or physical abilities. How can enhancing oneself be ethically evaluated? Some individuals may, for example, wish to enhance their ability to stay focussed 
over long periods of time by using psychiatric drugs; others may not. If one assumes that the consequences of the decision to enhance oneselfor not-are confined to oneself, on the basis of the autonomy principle alone, either preference is valid. In terms of justifying and evaluating this preference, nothing more can be said. If one follows a utilitarian premise, however, it becomes possible to evaluate these preferences on an inter-individual basis. If enhancement serves the interests of more people as compared to non-enhancement, then enhancement ought to be pursued and promoted. Thus, as is usually argued in the enhancement debate, following the utilitarian premise, the basically accidental preference to enhance oneself turns into an ethical, inter-individual obligation. Conversely, this also implies that the autonomous individual decision on whether or not to enhance oneself becomes a choice between courses of action that can be ethically assessed. In the case of a utilitarian assessment, carrying out enhancements would be seen as favourable, as long as the benefit-harm ratio of enhancement is better than that of non-enhancement.

In this way, an inter-individual, reason-providing ethics supplements the autonomy principle with content that guides actions, thereby making it possible to understand and reconstruct what it means to critically assess one's own preferences and those of others. On the basis of the autonomy principle alone, reflecting upon and debating preferences is a pointless undertaking, since in this case there are by definition no inter-individual reasons that could always serve as a shared basis for this reflection. Individuals may agree on a certain preference, but if they do not agree and do not find shared basic interests underlying their diverging preferences, the disagreement cannot be bridged. Supplementing the autonomy principle with a reason-providing ethics thus places all individuals in a shared space of reasons, in which debating preferences and reaching consensus are in principle always possible.

However, introducing a reason-providing ethics can also have negative consequences for autonomy. For example, one of the conundrums of the current enhancement debate is that each individual must be free to choose whether or not he or she wants to make use of these technologies. This is the case in the debate on reproductive enhancement, for example. The term "liberal eugenics" was introduced in this debate 
in order to highlight that it should be up to individual parents whether their offspring ought to be enhanced. ${ }^{1}$ At the same time, when arguments in favour of enhancement are based on utilitarian assumptions, as they often are, it follows that when enhancement results in benefits for the majority, it ought to be obligatory. It has been suggested, for instance, that if an enhancement drug of the future would allow surgeons to save more patients, the use of this drug could be made obligatory for this profession (Greely et al. 2008). In such cases, autonomy gives way to a reason-providing ethics, since nothing can be put forth in defence of autonomy apart from the fact that following ethical, in this case utilitarian, reason may not conform to the will of the individual. Now, changing the will of an individual in accordance with inter-individual reasons is what ethical demands and ethical reasoning are all about. Simply combining the autonomy principle with an interindividual reason-providing ethics account therefore necessarily weakens autonomy.

\section{No Conception of a Shared Good}

These relations highlight an important point. It becomes apparent that the autonomy principle is a non-ethical principle in the sense that it does not provide reasons for acting one way rather than another, provided the act does not directly interfere with the well-being of others. Under these conditions, the autonomy principle can provide no inter-individual reasons for preferring one specific course of action over another. As a correlate, the autonomy principle cannot provide any guidance for decision-making in these cases. The process of will-formation thus appears to be a matter of accident. Whatever comes to be one's interest is what guides one's decisions and must be accepted as such.

Someone who observes behaviour that they find puzzling or wrongheaded is not obliged to interfere, ask for reasons or try to convince the observed actor of the superiority of a different way of behaving. To take up an example provided by John Stuart Mill, if I observe someone who is headed towards a bridge and I know that it will collapse under the person's weight, I am not obliged to interfere, to ask why the person is put- 
ting himself into such a dangerous situation or to try to convince him that it would be better to stay away from the bridge. All these interventions would be based on the assumption that my preference not to plummet ought to be the other person's preference as well. However, this is clearly not the case, since the observed person is choosing to step on the bridge. As Mill argues, the only mistake I may presume the person walking is making is that he is not correctly informed about the bridge's condition. If I have provided him with this information and he keeps on walking anyway, further attempts to prevent him from his course of action must be seen as unwarranted interventions into his individual freedom (Mill 1869, chapter 5, p. 5).

The most fundamental way to express these characteristics and implications of the autonomy principle is to say that the autonomy principle does not include a conception of a shared or potentially sharable idea of a good life. Such an idea would justify attempts to understand and discuss reasons for acting one way rather than another. Interests could be understood as preliminary judgements on what ought to be regarded as good, which are then always open to revision. In contrast, following the autonomy principle, one may help others to fulfil their will if one is in a position to do so and if the other person asks for and needs help, regardless of how one assesses these aims oneself. The justification on which this option to help rests is that the end which the other person wants to realise is obviously in their interest and thus promotes what they regard as good for themselves. Conversely, if the person rejects an offer of help, such as a medical treatment, this is what they want, and no further attempts to change the will are called for. Attempts to alter what a person wants are confined to giving factual information. Doing more would have to be seen as unduly influencing the other person's will, since there is no way to understand this exertion of influence as part of what the other person themselves would do or wants to do. Giving reasons for alternative courses of action becomes an unwarranted act of intrusion as soon as these reasons do not refer to the given interests and preferences of the other person. In other words, according to the autonomy principle, reasons for actions are solely the given interests of the acting person. Inter-individual reasons cannot be part of the individual process of will-formation. 


\section{The Autonomy Dilemma}

The argument so far appears to end in a dilemma. Relying solely on the autonomy principle makes individual decision-making look like a speechless, almost mechanistic, or at least communication free activity. With regard to actions that do not directly harm others, no inter-individual, ethical reflection should make sense. However, if one introduces interindividual reason-providing ethics accounts in addition to the autonomy principle, these accounts necessarily tend to diminish the validity of autonomy, as the utilitarian reasoning in the enhancement debate shows. As the dilemma stands, one must choose between contingent autonomous will on the one hand and universally prescriptive ethical demands on the other.

Neither of the two alternatives fits very well with how humans actually tend to behave when confronted with individual therapeutic choices that have a significant impact on their future life. Patients can reflect upon such choices together with relatives, friends, or members of their health care team, without thereby sacrificing their autonomy to universal ethical demands. Quite the contrary, this inter-individual reflection on the good life is often the catalyst for truly autonomous choice. What is more, helping someone facing such a choice by supporting them and promising future support is often regarded as ethically valuable rather than as an intrusion into personal freedom. Hence what is needed is a concept of autonomy that can account for these phenomena and thus resolve the autonomy dilemma.

\section{Kant on Autonomy}

When looking for alternative concepts of autonomy, Kant's philosophy is a natural place to start. After all, it is Kant who explicitly uses the term "autonomy", whereas Mill, for example, speaks of freedom and individuality instead. For Kant, autonomy is not just the ability to act upon individual preferences and to grasp factual information that has relevance for how to accomplish an end. On the contrary, acting in accordance with one's autonomy for Kant is tantamount to acting ethically. This is because 
when one reflects on a possible action from the perspective of autonomy, one applies a test of practical reason, that is an ethical test, to this action, namely the test of universalisability. One is supposed to ask oneself whether what one plans to do could be done by everyone "without contradiction" (Kant 1996, p. 75, BA 57). According to Kant, this is a test which one must necessarily accept, because as a practically deliberating person one is part of the realm of universal practical reason, and in this realm, the only ethical criterion that does not rest on contingent preferences is the test of universalisability. Moreover, this test is not imposed on reason and practical reasoners from somewhere else, but originates within reason itself. It is a law that reason and oneself as a reasoner impose upon concrete cases of reason-guided will-formation and decision-making.

For example, refusing to help someone when help could be provided at no great cost to oneself cannot be universalised, according to Kant, since if this preference were a universal law, a situation could arise in which one would need help oneself and not receive it. Hence, Kant concludes that a world in which no one helps others might be thinkable without contradiction, but it cannot be desired without contradiction (Kant 1996, p. 75, BA 56). To take another example, the desire to take one's life when one's future appears to bring more harm than happiness is, following Kant, contradictory, since if everyone adopted this preference, humankind would extinguish itself and there would be no one left to formulate and pursue preferences at all. Therefore, he claims, this preference contradicts its own condition when universalised (Kant 1996, p. 73f, BA 53).

Much has been said for and against these examples and for and against Kant's approach to autonomy and ethics in general. In the context of the discussion here, namely with regard to the autonomy dilemma, Kant's approach initially appears to be a promising way to bring ethical content to the principle of autonomy and to understand will-formation as a reason-guided process. After all, autonomy is thought to involve ethical reasoning. Will-formation and decision-making about one's own future and well-being can be regarded as ethical reason-guided phenomena, as especially the second example above shows. Upon closer scrutiny, however, Kant's approach has serious limitations with regard to resolving the dilemma of ethical content. In order to resolve this dilemma, an account 
of autonomy is needed. On the one hand, this account must understand will-formation as a process that is guided by ethical reasons. On the other hand, this must be an open process in which certain solutions cannot be flagged as right or wrong without a deliberative, intersubjective exchange. Such an exchange should be held together by a justified sense of having a shared aim, but, at the same time, it must be assumed that right and wrong cannot be inferred from this shared aim without intersubjective deliberation.

Kant's use of the criterion of universalisability points in a different direction. The way in which he treats the question of whether it is ethically justified to take one's life if one's future life does not appear to be worth living is a case in point. He does not imagine this to be a weighing of multiple points of view or a process involving intersubjective social support. Rather he assumes that individually applying the test of universalisability inevitably leads to the conclusion that suicide is not ethically allowed. In other words, the shared aim of acting in accordance with the test of universalisability does not leave room for interpretation or different forms of concretisation in specific contexts as part of a process of intersubjective reason-guided communication.

What is more, critics have pointed out that contrary to Kant's own supposition, planned actions cannot be ethically justified or prohibited on the basis of the criterion of universalisability. These critics claim that Kant relies on implicit hidden assumptions that render planned actions non-universalisable. Therefore, the criterion of universalisability as such is empty. To take the two examples given above, someone who is willing to accept that he will not receive help in cases where he might need it might not see any contradiction if his preference not to help others were universalised. In the same vein, it can be argued that the assumed fact that a preference for suicide, if universalised, undermines the possibility of there being any wills is only a contradiction if one regards the existence of wills as undoubtedly desirable. ${ }^{2}$

It might be possible to save Kant from this criticism and perhaps also to develop an interpretation of his theory that can resolve the autonomy dilemma. ${ }^{3}$ However, since there are other philosophical accounts of autonomous will-formation that are better suited to resolve this dilemma from the start, it makes sense to turn to these approaches instead. 


\section{Hermeneutic Autonomy}

One way to escape the autonomy dilemma is to look for an understanding of individual will-formation that introduces reason and interindividual reflection as guiding factors in this process, without at the same time assuming a definite set of ethical norms that trump individual choice. Many accounts of the self that have been developed in hermeneutic philosophy can be read in this way.

Most notably, Paul Ricoeur sees will-formation as a reason-guided process. Reasons are not just given preferences. They always include a judgement about what is to be regarded as good in an inter-individual sense. If a certain course of action is judged as being good, any person in a similar situation ought to be able to follow this judgement, regardless of whether or not they initially have such a preference. The judgement need not be restricted to instrumental goodness, according to which an action is good if it serves as a means to bring about a desired state of affairs. "Good" also covers actions of which one assumes that they can be part of what constitutes a "good life' with and for others, in just institutions" (Ricoeur 1992, p. 172). Therefore, forming one's own will is potentially always an interindividual, communicative relation and contains a "dialogical dimension" (Ricoeur 1992, p. 180). Recognising and weighing reasons involves taking up the perspective of others. One does not begin decision-making with a fixed set of preferences that just need to be correctly informed in order to lead to what the individual then can regard as a good decision. On the contrary, decision-making starts as an always in principle open search for reasons which are formed by taking up a number of points of view through which one finds one's own perspective.

If this is a correct model of what it means to form a will, a debate about what is good is a seamless extension of the internal will-forming process. In such a debate, each standpoint functions as a reason that must be weighed and assessed, just as reasons and standpoints are internally assessed in the will-forming process. Hence, the result of a debate can have an influence on the individual will, regardless of the standpoint and preferences that made up this individual will in the first place. If someone is convinced by such a debate and changes their will accordingly, this is essentially identical to the process by which one forms one's will oneself. 
A pressing question for any such account is how one can settle the issue of what is to be regarded as good in a specific situation. Ricoeur does not assume a fixed set of norms that can help solve this problem, nor should finding a decision be a matter of power or contingency or other factors external to reflection. It is important to adhere to this claim, since otherwise debating the good becomes a matter of prescriptively declaring the good or settling for an arbitrary assumption of what should be regarded as good. One would then find oneself back in the dilemma mentioned above. Hermeneutic ethics thus presupposes a shared orientation towards the good that cannot directly be translated into concrete aims and actions but that nevertheless acts as a transcendent, only partly achievable point of consensus. According to Ricoeur, the ethical orientation towards a good life is just this: a shared orientation which can be assumed to be of universal validity, while its concrete meaning can differ and needs to be determined with regard to context. ${ }^{4}$

It may be helpful to compare this understanding of the notion of the good to the notion of truth in science. In scientific practice, "truth" functions as a universal guiding norm that shapes actions and debates. At the same time, whether one has reached the truth or not can always be called into question. Agreeing that one is looking for the truth thus does not settle arguments about what is to be regarded as true in specific circumstances. Nonetheless, it provides a general and universal aim that guides scientific inquiry and, as such, provides a shared basis for resolving conflict.

Hermeneutic autonomy stresses the procedural and inter-individual character of will-formation and decision-making. Due to this shift of focus, hermeneutic autonomy does not dissolve individual will-formation into contingent autonomous willing, nor does it subject autonomy to a prescriptive, overarching ethical norm that in itself defines what a good will ought to look like. In this way, it escapes the autonomy dilemma.

This kind of an account of autonomy contains the idea of a good which, firstly, need not already be present in the form of given preferences, and which, secondly, can be grasped and shared by exchanging reasons inter-individually. Nonetheless, such an account does rest on non-trivial metaphysical assumptions-as does any theory that incorporates an idea of truth or truth-seeking that is intended to have an effect 
on action. It is important to be aware of this point, since these metaphysical assumptions are one of the main reasons for objecting to these approaches in philosophical debates. ${ }^{5}$ A discussion of these implications must be left aside here, however.

\section{Enabling Autonomy}

From this perspective, making up one's mind and acting autonomously does not consist in determining and following contingently given preferences and being equipped with relevant factual knowledge. Rather, forming an autonomous will means taking part in an ongoing dialogue. This dialogue need not be restricted to verbal communication and it need not always take place between co-present interlocutors. Convictions may be expressed nonverbally and affectively, and one may find convincing attitudes and perspectives in books, films or other media. In any case, when forming a will, one is positioning oneself in this dialogue and finding one's own standpoint and voice.

Respecting autonomy thus initially requires safeguarding the ability to develop and enact autonomy, that is to say granting the other person a place in the debate, listening, revealing one's own perspective and taking the time to let the exchange evolve. At some later point, then, respecting autonomy will also entail refraining from intervening if a person has decided themselves that these actions do not harm others.

In the medical context, these presuppositions of autonomy can be translated into calls for caution and attention. For example, before following a patient's request to end life-prolonging or life-saving treatment, one ought to make sure that the patient has had time to think for themselves, the opportunity to talk to others, and, not least, that they are assured that their future existence and well-being matters. The latter entails that once a patient has reached a final decision, this decision must be regarded as authoritative. However, it also entails that the patient be assured that they will not be left alone or be perceived as a burden, should they decide to accept treatment.

Respecting autonomy thus incorporates an orientation towards wellbeing. It is directed at physical, psychological, and social presuppositions 
of autonomy. In what is to follow it will be argued that this understanding of what it means to respect autonomy is at its heart an understanding of care.

\section{Care in Medical Ethics}

The Oxford English Dictionary defines care as the "provision of what is necessary for the health, welfare, maintenance, and protection of someone or something" (Oxford Living Dictionaries 2016). Care ethicists Tronto and Fischer characterise care in the same vein as "a species of activity that includes everything we do to maintain, contain, and repair our 'world' so that we can live in it as well as possible" (Fisher and Tronto 1990, p. 40). Today's standard medical ethics approach, as introduced by American scholars Beauchamp and Childress, refers to the principles of autonomy, beneficence, non-maleficence and justice. As mentioned, care is prominent in the principles of both beneficence and non-maleficence. Beneficence calls on physicians to offer and apply only those therapies that promise to improve the patient's well-being. Non-maleficence additionally demands that medical interventions ought to have as few side effects as possible. These two principles are thus oriented towards patient well-being and contend that well-being ought to be preserved or restored, not compromised. In other words, these principles describe what care amounts to and demands.

Now, from a standard medical ethics interpretation, basing medical ethics solely on care runs the risk of justifying paternalistic attitudes and behaviour. If well-being in medicine is defined in terms of disease and illness, the experts on questions of patient well-being are the members of the healthcare team, since it is the healthcare professionals who are trained to diagnose and treat a disease and professionally care for the patient accordingly. In this scenario, it appears that healthcare team members can determine by themselves what must count as well-being for a patient. Consequently, treating and caring for a patient appears to be an activity that can be pursued independently from what the patients wants and regards as good. Restoring health is considered good for the patient, and the healthcare team itself is in the best position to judge how to accomplish this. 
As a matter of fact, however, patients at the end of life may not always want to extend therapy as far as medically possible. Patients at risk of developing a disease may not always consider a strict regimen of daily preventive routines to be worth the effort. Other patients may reject specific medical interventions for religious reasons. That is to say, what constitutes well-being for an individual patient depends on how she or he values health, disease, preventive efforts, and quality of life. Stressing autonomy in medical ethics helps to incorporate this fact into healthcare practice. Following this reasoning, autonomy can be introduced as a counterbalance to care in order to push back the ethically dubious paternalistic tendencies of a solely care-based ethics.

\section{The Care Dilemma}

Nonetheless, this strategy for dealing with the supposed paternalistic tendencies of a care-based approach to medical ethics leads into a specific variation of the dilemma developed above. If one sees autonomy as prevailing over care, it becomes unclear why autonomy should be restricted to rejecting medical interventions. As long as patient preferences do not harm others, why should theses preferences not be justified? From the point of view of the autonomy principle, there can be no meaningful debate about the patient's preferences, neither based on supposedly interindividually valid evaluations of health states, nor based on any other supposedly inter-individually valid reasons. If, however, one gives precedence to care, it must appear irrational, for example, to accept a patient's request not to undergo treatment when successful medical therapy is still possible. If the patient makes recourse to his own well-being, health care team members will be entitled to correct him or her, since defining wellbeing is, qua the hypothesis, part of their expertise.

What is needed in order to resolve the dilemma is an understanding of care that allows for reason-based debate about patient needs and preferences, without shifting the expertise on what is good for the patient completely into, in this case, the realm of medical and healthcare expert knowledge. Again, the hermeneutic understanding of autonomy is a viable option for resolving this dilemma. Approaching 
this concept from the perspective of care allows one to focus on the concept's ethical content.

Following Ricoeur, it is possible to understand autonomy as an internal dialogical process in which reasons and points of view on the good life are taken up and tested, thereby forming one's own voice. Engaging with and forming one's own will is thus inseparable from taking other perspectives into account. In his further reflection, Ricoeur equates this relation of self and other with the basic evaluational attitude of esteeming oneself and esteeming others. Indeed, one of Ricoeur's main aims is to show how being concerned with one's own will is inextricably intertwined with being concerned with the autonomy of others. When one is concerned with one's own good life, one esteems this life, and one does so also from the point of view of others. Conversely, if one cannot esteem oneself from the point of view of others and is not esteemed by others, one will not be able to esteem oneself (Ricoeur 1992, pp. 192-194). This is the reason why supporting autonomous will-formation can actually be regarded as a valuable aim from the point of view of an autonomous will. Esteeming oneself in autonomous will-formation is intimately linked to being esteemed by others and esteeming others, and ascribing to them the same abilities that one ascribes to oneself as an actor: "This exchange authorizes us to say that I cannot myself have self-esteem unless I esteem others as myself. 'As myself' means that you too are capable of starting something in the world, of acting for a reason, of hierarchizing your priorities, of evaluating the ends of your actions, and, having done this, of holding yourself in esteem as I hold myself in esteem" (Ricoeur 1992, p. 193). Respecting the autonomy of another thus leads to supporting the social and physical presuppositions of this kind of internal dialogue. This turn does not rest on an ethical demand that is external to what one values in autonomy. Instead, it develops within the autonomy stance itself, since autonomy presupposes esteeming others as one esteems oneself. These presuppositions can be regarded as constituting basic human needs that must be present in order to allow for autonomous will-formation.

A hermeneutic conception of care thus resolves the care dilemma by calling for attention to needs. However, these needs cannot be defined independent of the preferences of the other. First, there are physical and social needs that must be fulfilled in order to enable autonomous 
will-formation in general. Second, preferences might conflict with one another or with some of those very needs. Such preferences may appear puzzling from the point of view of hermeneutic care, or any understanding of care indeed, but since the aim of hermeneutic care is to enable and sustain autonomy, these preferences will have to be respected as long as due care has been taken to ensure that these preferences are not the premature results of unfulfilled social or physical needs. Care responds to needs, hermeneutic care responds to needs which enable and sustain autonomy. This specification prevents hermeneutic care from turning into paternalistic neglect of patient autonomy.

According to this account of care, caring for a patient is, first of all, caring for individual well-being insofar as it can be regarded to be a prerequisite of the ability to form a will. Health, for example, can be understood as a prerequisite of this kind. Nonetheless, humans have a capacity to individually reflect upon these prerequisites, to reject, transform, or prioritise them. Some may think there are reasons to strive for super-human powers and medical enhancements of their physical abilities. Others may regard rejecting medical treatment as the best option in their situation. Since wanting to reject a promising treatment appears to run counter to well-being, when caring for a patient one will have to learn more about why the patient prefers this option. There may be social or medical circumstances that lead to this preference which disguise an otherwise present wish to receive therapy and which one may be able to change. Caring for the patient hence involves engaging with the patient and being attentive. If one ultimately learns, however, that the kind of life that the patient will be able to have after successful treatment does not correspond to what the patient thinks of as valuable and meaningful, even if all medical and social supportive measures are in place, hermeneutic care entails refraining from attempts to override this decision, since hermeneutic care is not bound to a supposed objectively given well-being but aims at enabling and sustaining autonomous decision-making. If such a decision in a borderline case like this turns against its own prerequisites, this is disturbing. Yet ultimately, if supporting measures do not change the decision, it bears witness to what autonomous human reflection is capable of, namely neglecting itself. 
In these cases, patients do not want for themselves what the health care team regards as necessary. It has been argued from the point of view of hermeneutic care that these preferences must ultimately be accepted. It is also worth noting that in cases in which the prerequisites of the autonomous will-formation of others are under threat, hermeneutic care has the resources to draw boundaries. Generally speaking, the closer an action or intention comes to threatening the very conditions of an individual to take part in a verbal or non-verbal communicative exchange of equals about reasons for actions, the more it becomes ethically dubious. At this point, Ricoeur makes use of the "golden rule". He argues that the essence of this rule is to prohibit all those actions that deprive the other of his status as an equal other in an interactive of process of determining the good. He names as examples a descending slope from influence to the betrayal of friendship and faithfulness, threat, constraint, torture and murder (Ricoeur 1992, p. 220f). All these acts are infringements on the ethical demand to treat the other just like oneself, as someone who is capable of reflecting, evaluating, and esteeming oneself and others.

\section{Conclusion}

Construing autonomy as an ethical principle along the lines of a Millean account leads to a dilemma. Relying solely on this principle makes individual decision-making look like a speechless, almost mechanistic, or at least communication free activity. However, if one introduces interindividual reason-providing ethics accounts in addition to the autonomy principle, these accounts necessarily tend to diminish the validity of autonomy. As the dilemma stands, one must choose between contingent autonomous will on the one hand and universally prescriptive ethical demands on the other.

A hermeneutic understanding of autonomy can help us to escape this dilemma. Following Ricoeur, it can be argued that individual willformation is a reason-guided process that necessarily involves taking the perspectives of others into account. This also holds true in those cases in which the consequences of an action or intention are exclusively borne by the actor him- or herself. Individual will-formation is directed towards 
the idea of a good life, the content of which cannot be determined independent of others' preferences and perspectives. Respecting autonomy, then, leads to enabling and sustaining the individual will-formation process, which is to say it leads to caring for the physical and social prerequisites of individual will-formation. Respecting autonomy, thus, comprises care. It comprises a caring attitude towards others whose autonomous will-formation is to be enabled and sustained to the greatest extent possible.

Focusing on care as prime ethical principle can, in turn, once again lead to a dilemma, since care is a reaction to needs that might appear to be objectively identifiable. This is a variation of the autonomy dilemma named above. If one gives precedence to care, it must appear irrational, for example, to accept a patient's request not to undergo treatment when successful medical therapy is still possible. If the patient makes recourse to his own well-being, health care team members will be entitled to correct him or her, since defining well-being is, qua hypothesis, part of their expertise. In contrast, if one takes recourse to a Millean account of autonomy here, it becomes unclear why autonomy should be restricted to rejecting medical interventions.

What is needed in order to resolve the dilemma is an understanding of care that allows for reason-based debate about patient needs and preferences without shifting the expertise on what is good for the patient completely into, in this case, the realm of medical and healthcare expert knowledge. Again, the hermeneutic understanding of autonomy is a viable option to resolve this dilemma. Approaching this concept from the side of care allows one to focus on the concept's care-related ethical content.

Following this line of argument, it becomes apparent that respecting the autonomy of others can be derived as an ethical demand from an understanding of individual will-formation. If one grants Ricoeur's assumption that concern for finding one's own point of view on what constitutes a good life implies esteeming oneself, then esteeming others and their points of view is a necessary part of individual will-formation, since will-formation consists of taking other perspectives into account, testing them and thereby aligning with all those who have, have had and can have a voice in this inter-individual process. Furthermore, according to this account of 
care, caring for a patient involves, first of all, caring for individual wellbeing insofar as this can be seen as a prerequisite of individual will-formation and its intersubjective, dialogical structure. These constituents of well-being may, to a large degree, be common to all humans. Health, for example, can be understood as a prerequisite of this kind. Yet if one ultimately learns that the kind of life that the patient will be able to have after successful treatment does not correspond to what the patient thinks of as valuable and meaningful, even if all medical and social supportive measures are in place, hermeneutic care entails refraining from attempts to override this decision, since hermeneutic care is not bound to a supposed objectively given state of well-being but aims at enabling and sustaining autonomous decision-making. If such a decision in a borderline case turns against its own prerequisites, this is disturbing, but ultimately, if supporting measures do not change the decision, it bears witness to what autonomous human reflection is capable of, namely neglecting itself.

\section{Notes}

1. Nicholas Agar introduced this term in Agar (2004).

2. The locus classicus of this criticism is to be found in the writings of Hegel (Hegel 1977, p. 256).

3. Most famously, Onora O'Neill has supplied a defence of a Kantian concept of autonomy in ethics and bioethics especially (O’Neill 2002).

4. Ricoeur makes use of the Aristotelian concept of phronesis to make this point (Ricoeur 1992, p. 177). He stresses that living up to this ethical aim requires "unending work of interpretation" (Ricoeur 1992, p. 179).

5. Ricoeur touches on this issue when he writes: "What we are summoned to think here is the idea of a higher finality which would never cease to be internal to human action" (Ricoeur 1992, p. 179).

\section{References}

Agar, N. (2004). Liberal Eugenics. In Defence of Human Enhancement. Oxford: Blackwell.

Beauchamp, T. L., \& Childress, J. F. (2013). Principles of Biomedical Ethics. Oxford: Oxford University Press. 
Fisher, B., \& Tronto, J. (1990). Toward a Feminist Theory of Caring. In E. K. Abel \& M. K. Nelson (Eds.), Circles of Care. Work and Identity in Women's Lives. Albany: State University of New York Press.

Greely, H., Campbell, P., Sahakian, B., Harris, J., Kessler, R., Gazzaniga, M., \&

Farah, M. J. (2008). Towards Responsible Use of Cognitive-Enhancing Drugs by the Healthy. Nature, 456, 702-705.

Hegel, G. W. F. (1977). Phenomenology of Spirit (A. V. Miller, Trans.). Oxford: Oxford University Press.

Kant, I. (1996). Groundwork of the Metaphysics of Morals. In Kant, I., Practical

Philosophy (M. J. Gregor, Ed. \& Trans.). Cambridge: Cambridge University Press.

Mill, J. S. (1869). On Liberty. London: Longman, Roberts \& Green.

O’Neill, O. (2002). Autonomy and Trust in Bioethics. Cambridge: Cambridge University Press.

Oxford Living Dictionaries. (2016, December 16). English. Entry “care (noun)”. Retrieved from https://en.oxforddictionaries.com/definition/care Ricoeur, P. (1992). Oneself as Another. Chicago: The University of Chicago Press.

Open Access This chapter is licensed under the terms of the Creative Commons Attribution 4.0 International License (http://creativecommons.org/licenses/ by/4.0/), which permits use, sharing, adaptation, distribution and reproduction in any medium or format, as long as you give appropriate credit to the original author(s) and the source, provide a link to the Creative Commons license and indicate if changes were made.

The images or other third party material in this chapter are included in the chapter's Creative Commons license, unless indicated otherwise in a credit line to the material. If material is not included in the chapter's Creative Commons license and your intended use is not permitted by statutory regulation or exceeds the permitted use, you will need to obtain permission directly from the copyright holder.

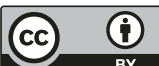

